\title{
Diagnostic value of 'optic foramen views': experience from an eye hospital
}

TABLE I Optic foramen views: indications and findings

\begin{tabular}{|c|c|c|c|c|c|}
\hline \multirow[t]{2}{*}{ Indication } & \multirow[t]{2}{*}{ Number } & \multicolumn{4}{|l|}{ Findings } \\
\hline & & Normal & Abnormal & Equivocal & Unknown \\
\hline Visual disturbance & 124 & 119 & 4 & 1 & \\
\hline Proptosis/orbital mass & 20 & 16 & 2 & & $2^{\star}$ \\
\hline Orbital pain/headache & 10 & 10 & & & \\
\hline Swollen or cupped discs & 7 & 7 & & & \\
\hline Eye movement disorder & 7 & 7 & & & \\
\hline $\begin{array}{l}\text { Unknown } \\
\text { Trauma }\end{array}$ & $3^{*}$ & & & & \\
\hline $\begin{array}{l}\text { Trauma } \\
\text { Epilepsy }\end{array}$ & 1 & & 1 & & \\
\hline Neurofibromatosis & 1 & 1 & & & \\
\hline Total & 174 & $162(93 \cdot 5 \%)$ & $7(4 \%)$ & $1(0 \cdot 5 \%)$ & $4(2 \%)$ \\
\hline
\end{tabular}

${ }^{\star}$ Documents unavailable.

TABLE II Abnormalities on optic foramen views in 7 cases

\begin{tabular}{|c|c|c|}
\hline Indication & Abnormality & $\begin{array}{l}\text { Findings on } \\
\text { other studies }\end{array}$ \\
\hline $\begin{array}{l}\text { Visual loss } \\
\text { Optic atrophy }\end{array}$ & $\begin{array}{l}\text { Air in globe } \\
\text { Ipsilateral superior orbital } \\
\text { fissure large }\end{array}$ & $\begin{array}{l}\text { Skull: air in globe } \\
\text { Skull: superior orbital fissure } \\
\text { large }\end{array}$ \\
\hline $\begin{array}{l}\text { Blurred vision } \\
\text { Optic disc hypoplasia }\end{array}$ & $\begin{array}{l}\text { Both canals enlarged } \\
\text { Ipsilateral canal small }\end{array}$ & Skull and CT: empty sella \\
\hline $\begin{array}{l}\text { Trauma } \\
\text { Optic nerve glioma } \\
\text { Orbital mass }\end{array}$ & $\begin{array}{l}\text { Ethmoid fracture } \\
\text { Ipsilateral canal large } \\
\text { Frontal sinus mucocele }\end{array}$ & $\begin{array}{l}\text { Skull: ethmoid blowout } \\
\text { CT, MRI: glioma, large canal } \\
\text { Skull: frontal sinus mucocele }\end{array}$ \\
\hline
\end{tabular}

Department of Radiology, Moorfields Eye Hospital, City Road, London EC1V 2PD I Moseley

Correspondence to: Dr I Moseley

Accepted for publication 9 November 1989

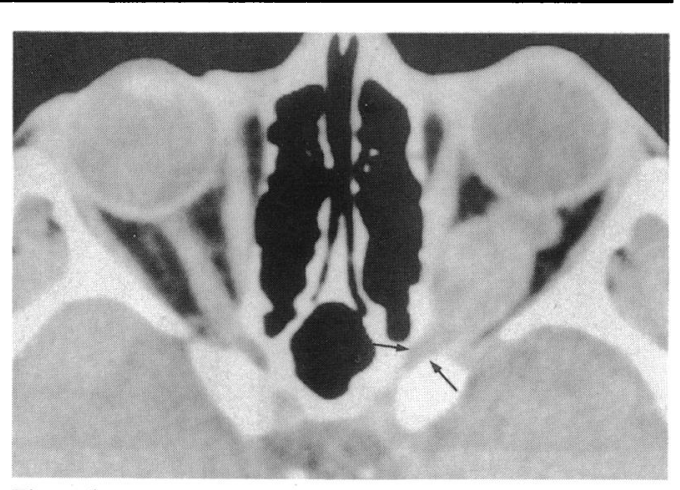

Figure la

\begin{abstract}
A prospective survey of 174 consecutive patients in whom plain radiographs of the optic canals were requested by ophthalmologists disclosed no cases in which these films made a positive contribution to management. It is suggested that as a general rule this radiographic examination has no useful role.
\end{abstract}

Conventional radiographs of the optic canals, popularly referred to as 'optic foramen views, are time consuming, and involve a small but . cases they contribute little, if at all, to management. They have been almost totally

Figure 1: A girl aged 15, diagnosed some years previously as having a glioma of the left optic nerve. (a) Contrast-enhanced axial $C T$ showed the large retrobulbar tumour funnelling down into the enlarged left optic canal (arrows). (b) Optic canal views performed on a subsequent visit again demonstrated the enlargement of the left canal. abandoned by neurologists and neurosurgeons ${ }^{1}$ but not by ophthalmologists, whose recourse to computed tomography, for example, may be less ready. The present study was designed to establish when, or if, they are indicated.

\section{Material and methods}

As part of a wider prospective survey a record was kept of the indications and findings in patients referred to the radiology department for 'optic foramen views' between January and December 1988. No specific radiological control was exercised on referrals during that time. The findings were those of a consultant ophthalmic radiologist or, in about $10 \%$ of cases, of one of two neuroradiological senior registrars. A record was also kept of the findings on any other imaging procedure (other than orbital sonography) to which these patients were subjected during the review period.

\section{Results}

Plain films of the optic canals were requested for 174 patients, for all but three of whom skull films were also obtained. The indications for and the findings on the optic foramen views are shown in Table I.

There were seven cases in which the optic canal views were thought to be abnormal (Table II). One of these was a child known for many years to have a glioma of the optic nerve in whom CT had shown the tumour to extend into the optic canal (Fig 1), and in another child a small optic canal on the affected side was associated with optic disc hypoplasia (Fig 2). In a young woman with an episode of blurred vision and normal optic discs bilateral enlargement of the optic canals was thought possibly to be the consequence of dilatation of the optic nerve sheaths, indicating chronic increase in intracranial pressure. No clue to aetiology was given by the plain films, though CT showed an empty sella turcica (Fig 3).

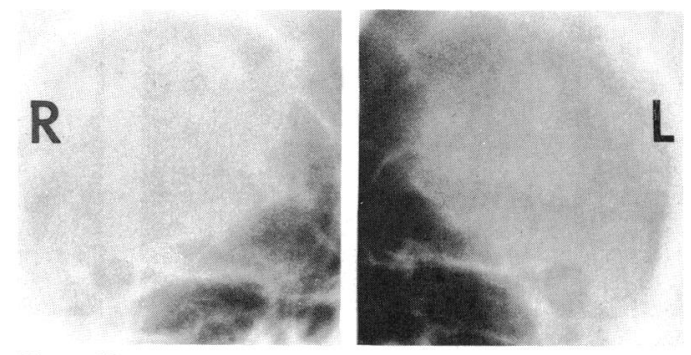

Figure 1 
The abnormality visible on the coned views in the remaining patients did not affect the optic canals and was also evident on the skull radio-
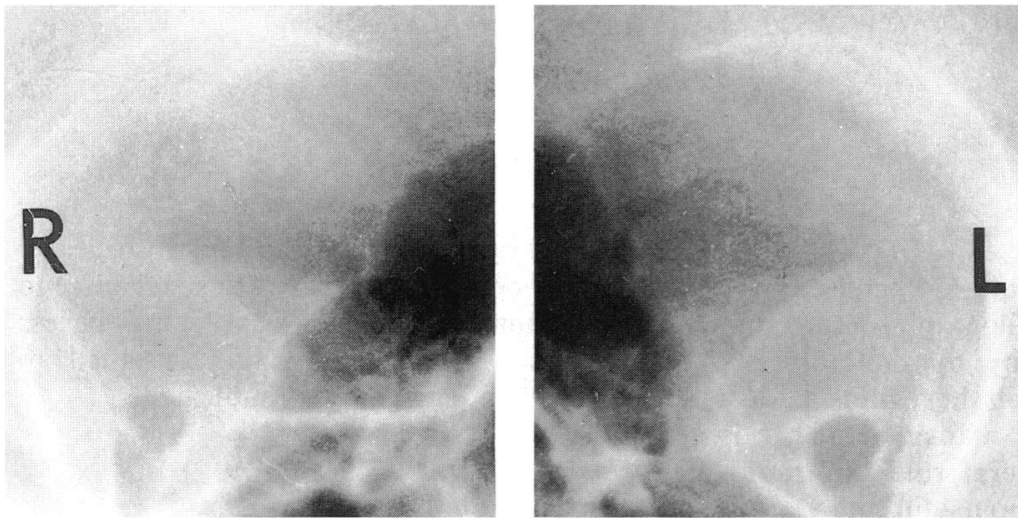

Figure 2: A 3-year-old boy was noted to have poor vision in the right eye, but funduscopy, performed with suboptimal co-operation, was thought to be normal. The optic canal views showed the left side to be normal, while the right canal was small. Further examination by a paediatric neuro-ophthalmologist, unaware of the radiographic findings, revealed a hypoplastic optic disc on the right.
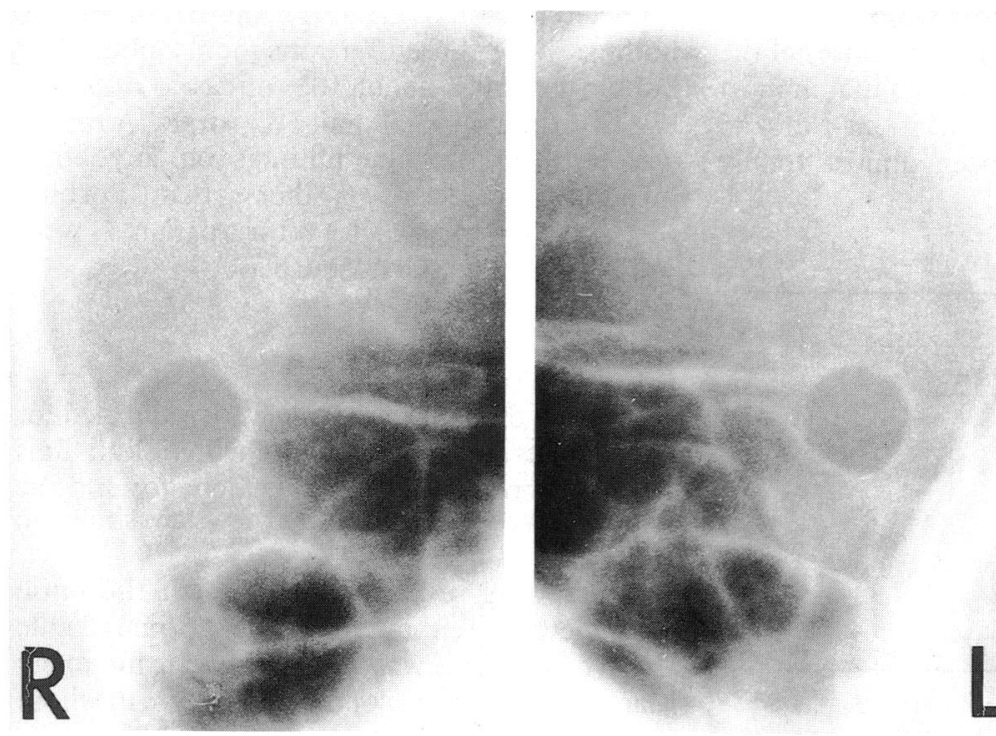

graphs. In six patients with visual disturbance and in two with intraorbital mass lesions the skull radiograph and/or other tests were abnormal, while the optic foramen views were interpreted as normal. CT was carried out in one patient because of erroneous interpretation of the optic foramen views by an ophthalmologist. It confirmed the normality of the plain films reported by the radiologist. Questionable findings reported in one further case were not confirmed by subsequent investigations.

There were thus no cases in which abnormalities shown by the optic canal radiographs, not evident clinically or on other simple imaging tests, contributed positively to patient management.

\section{Discussion}

'Careful study of routine skull $x$-rays and optic canal views may yield vital diagnostic information (in patients with optic nerve compression) and

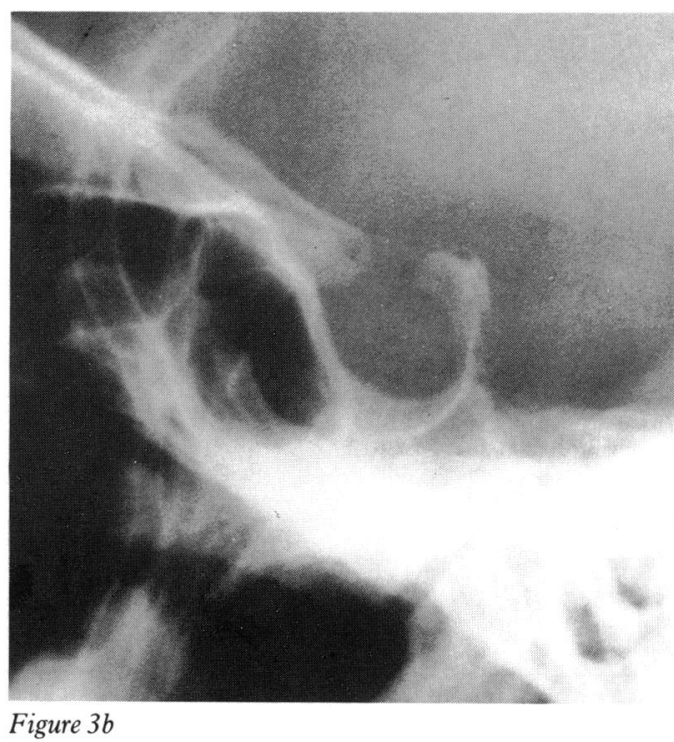

Figure $3 b$

Figure 3c

Figure 3: A 31-year-old woman presented with an episode of blurred vision. Both optic canals (a) appeared large and rounded, and the sella turcica was deep, with a double floor, suggesting an 'empty sella' $(b)$. These two findings raised the possibility of benign intracranial hypertension with dilatation of the optic nerve sheaths. However, the patient had never experienced headaches, the optic discs were completely normal, and CT (c), while confirming the empty sella (arrow), was also normal. 
should under no circumstances be omitted'. ${ }^{2}$ With improvements in the quality and availability of CT and the introduction of magnetic resonance imaging (MRI) this view has been overtaken by history, and in neurological practice plain films are used with ever decreasing frequency. ${ }^{13}$

Unlike skull or chest radiographs, optic foramen views have no useful screening role: they are specifically designed to show, with minimal distortion, changes in size or shape of the optic canals or in the density or texture of the surrounding bone, and are indicated, if at all, in the assessment of unilateral optic neuropathy. ${ }^{4}$ Thus, while patients with orbital pain, headache, bilateral papilloedema, eye movement problems, and even epilepsy account for less than $15 \%$ of those referred for optic foramen views in the present series, these referrals would appear to have no anatomical or physiological basis. Similarly, adults with proptosis or palpable orbital masses in whom vision is not severely affected (12 cases in the present series) are unlikely to benefit from radiography of the optic canals.

Orbital CT is very rarely positive in patients with unilateral visual loss and no other signs of an orbital mass lesion. ${ }^{5}$ Moreover, visual loss due to lesions confined to the optic canal, without orbital involvement, is inordinately rare. ${ }^{6}$ In the present series there were more cases in which a significant lesion was not shown by the optic foramen views than true positives, but these cannot reasonably be classified as false negatives, since the examination failed to show abnormalities for which it was not designed.

A patient with unexplained visual loss requires a definitive examination such as CT or MRI. Since plain films are normal more often than not in patients with orbital meningiomas, ${ }^{7}$ so that neither positive nor negative results on optic foramen views should obviate further imaging investigations, the plain films can be dispensed with entirely, without prejudice to the patient.

It may be argued that in children with optic pathway gliomas plain radiography is a simple way of assessing enlargement of the intracanalicular portion of the optic nerve, but in cases in which this information will modify management MRI is probably more sensitive. In the group reviewed here only two of the patients (one of whom did not have visual symptoms) were under 10 years old, and there were a further six aged under 20.

The radiation dose from adequate optic foramen views is of the order of 1-2 cGy, but repeat exposures are not uncommon, and since skull films are usually requested at the same time the effective dose to the lens from the latter examination $(2 \mathrm{cGy})^{8}$ might often be more than doubled. There is no reason to suppose that the series of consecutive patients involved in this prospective study are in any way exceptional, and the conclusion that there is no role for diagnostic optic foramen views would seem inescapable.

1 Moseley IF. Long term effects of the introduction of noninvasive investigations in neuroradiology. Part 2: Effects on management of individual patients. Neuroradiology 1988; 30: 193-200.

2 Sanders MD, Moseley IF. CT scanning in neuroophthalmology: optic nerve compression. In: Thompson HS, ed. Topics in neuro-ophthalmology. Baltimore: Williams and ed. Topics in neuro-ophth

3 Moseley IF. Long term effects of the introduction of noninvasive investigations in neuroradiology. Part 1: Overall trends. Neuroradiology 1988; 30: 187-92.

4 Hartmann E, Gilles E. Radiodiagnostic en ophtalmologie. Paris: Masson, 1955.

5 Moseley IF. The contribution of $x$-ray computed tomography to the diagnosis and management of orbital disease. Orbit 1986; 5: 149-52.

6 Moseley IF. Diagnostic imaging in neurological disease. Edinburgh: Churchill Livingstone, 1986.

7 Macpherson P. The radiology of orbital meningioma. Clin Radiol 1979; 30: 105-10.

8 Isherwood I, Young IM, Bouker KW, Bramall GK. Radiation dose to the eyes of the patient during neuroradiological investigations. Neuroradiology 1975; 10; 137-41. 